\title{
Influence of soil moisture and plant roots on the soil infiltration capacity at different stages in arid grasslands of China
}

Yu Liu ${ }^{\mathrm{a}, \mathrm{b}}$, Zeng Cui ${ }^{\mathrm{a}, \mathrm{b}}$, Ze Huang ${ }^{\mathrm{a}, \mathrm{b}}$, Manuel López-Vicente ${ }^{\mathrm{c}}$, Gao-Lin Wu ${ }^{\mathrm{a}, \mathrm{b}, \mathrm{d}, *}$

${ }^{a}$ State Key Laboratory of Soil Erosion and Dryland Farming on the Loess Plateau, Northwest A \& F University. Yangling, Shaanxi 712100, China

${ }^{b}$ Institute of Soil and Water Conservation, Chinese Academy of Sciences and Ministry of Water Resource. Yangling, Shaanxi 712100, China

${ }^{c}$ Department of Soil and Water, Experimental Station of Aula Dei, EEAD-CSIC. Zaragoza 50059, Spain

${ }^{d}$ CAS Center for Excellence in Quaternary Science and Global Change. Xi'an 710061, China

* Corresponding author at: Institute of Soil and Water Conservation, Chinese Academy of Sciences and Ministry of Water Resources, 26 Xinong Road, Yangling, Shaanxi 712100, P. R. China; E-mail address: gaolinwu@gmail.com / wugaolin@nwsuaf.edu.cn (G.L. Wu). Phone : 86-29-87012884 / Fax: 86-29-87016082

Received 24 January 2018; Received in revised form 25 June 2019; Accepted 26 June 2019 Available online 3 July 2019: https://www.sciencedirect.com/science/article/pii/S0341816219302899 Published online in Elsevier ScienceDirect: https://doi.org/10.1016/j.catena.2019.104147

CATENA Volume 182, November 2019, 104147.

RUNNING TITLE: Moisture and roots affect soil infiltration

\section{HighLights:}

- Soil moisture and plant roots determined soil infiltration capacity by stages were studied.

- Soil moisture is a main factor to influence negatively infiltration capacity in initial stage.

- Soil moisture and plant roots codetermined the infiltration rate in steady stage.

- Influences of soil moisture and roots are diminishing with the duration of infiltration time. 


\section{Abstract}

The accurate measurement of soil infiltration rates is a challenging task in hydrological studies, as they are governed by complex interactions between the plant and soil components. To explore the effects of plant roots and soil moisture (SM) on infiltration process, an automatic measurement system based on a point source device was used to determine infiltration rates at different cultivated grasslands (leguminous, gramineous and mixed) in an arid region of China. The results showed that SM and plant roots significantly affected the infiltration process at different stages in the three grasslands. The soil infiltration rates were negatively correlated to SM, but a positive correlation was observed with the below-ground biomass (BGB). SM was the main factor influencing the infiltration rates in the initial stage of infiltration, whereas both SM and BGB determined the steady-state infiltration rates. The influence of the combined effects of SM and plant roots decreased over infiltration time. The decreased rate of determining coefficient showed that SM was more influent than plant roots. These results may contribute to interpret the observed higher soil infiltration capacity in the leguminous grasslands than in the gramineous and the mixed grasslands, and were conducive to better understand the effects of plant and soil properties on infiltration processes in arid areas.

Keywords: Soil infiltration rate; soil moisture; root systems; infiltration process; grassland; arid region

\section{Introduction}

Infiltration is the process of water penetration into the soil profile, and is a major component of the hydrologic cycle by linking overland flow and groundwater recharge as part of the terrestrial water cycle. The process of infiltration is affected by water supply and soil 
permeability, which determines the amounts of water entering into the soil profile from the surface runoff (Lei et al., 2006; Ebel and Moody, 2013). Comprehension of the infiltration processes is important for an efficient irrigation design and management, overland flow estimation, the balance of the soil water reservoir, and to evaluate the movement of fertilizers and pollutants between the different soil horizons, and downwards from non-point source areas (Mao et al., 2016). Quantification of soil infiltration rates is important for ecologists to figure maintenance of ecosystems, such as grasslands (Ng et al., 2013; Fischer et al., 2014; Wu et al., 2016; 2017), forests (Leung et al., 2015), and croplands (Capowiez et al., 2009).

The definition of soil infiltration performance is the infiltration flux of per unit area under atmospheric pressure and adequate water supply (Lei et al., 2006; Assouline, 2013). The maximum infiltration capacity is obtained when water infiltration into the soil approaches to a constant rate, commonly after the soil surface is ponded, and thus water infiltration is the greatest (Youngs, 1991). There are a large number of soil factors that affects soil infiltrability, such as soil texture, structure, the mineral composition, and soil moisture (SM) in the soil profile. These factors may impact infiltration process by favouring soil surface seal formation, which is formed from the physical compaction and physicochemical dispersion processes due to the raindrop impacts during a rainfall event (Liu et al., 2011). In general, the hydraulic conductivity of the surface-sealed is much lower than that observed in the below topsoil layers, and thus sealed surfaces restrict water infiltration (Liu et al., 2011; Fischer et al., 2014). The base for measuring the soil water infiltration rate (IR) is supplying sufficient water onto the soil surface to reach the actual infiltration rate of that soil. When the water supply rate is lower than IR, the measured IR is equal to the inflow rate of water (Mao et al., 2011). The dynamics of soil 
water infiltration are governed by both energy and mass transport processes, and initial soil moisture plays an important role in producing the mass and energy gradients (Fouli et al., 2013). An increase in soil moisture diminishes the hydraulic gradient thus decreasing the driving force responsible for water infiltration into the soil (Liu et al., 2011). Therefore, soil infiltrability can be considered as a soil characteristic that depends on the initial soil water content profile (Thompson et al., 2010). However, quantifying IR in natural environments has much great challenges due to the effects of complex multi-factors and the significant spatial variability of the values of soil physical and chemical parameters.

The accurate measurement of IR is required in hydrology, agricultural engineering and soil water conservation. Many direct and indirect methods have been conducted to determine IR. Recent researches have achieved significant progresses in the measurement of IR (Angulo-Jaramillo et al., 2000). Commonly used methods for IR are the double-ring method, the single-ring method, rainfall simulators, disc permeameter, and the point source method. Each method has weaknesses and strengths (Table 1). Besides, the field use of these methods is limited either due to the short duration of the steady-state experiments that cannot be conducted in soils with a low conductivity or due to the great amount of water required in the soils with a high hydraulic conductivity for maintaining sufficient water supply (Cheng et al., 2011). Therefore, there is not a perfect method to measure IR due to the numerous factors affecting infiltration during the infiltration process. These traditional methods cannot measure the whole infiltration process, but most disadvantages have been overcome basically by the point source method. This technique has been applied to measure soil infiltration in-situ hydraulic properties (Shani et al., 1987; Revol et al., 1997; Lubana and Narda, 2001; Su, 2007). Mao et al. (2016) 
introduced a new approximate point source method for estimating the IR during the complete infiltration process. This enhanced method determines IR through forming a circular or nearly circular shaped wet area, which expands gradually over time to reach a final wet area. This point source method determines the IR by calculating the average value within the ponded area. Compared with linear source methods, the point resource showed higher accuracy because the relative errors of the experiments were all less than 2.5\% (Mao et al., 2016). The point source method needs very little water and time, and thus it is a useful tool for field experiments. This point method has been used to determine the effects of below-ground biomass (BGB) and root channels on soil infiltration capacity under similar soil water conditions in arid reclaimed mine soils (Wu et al., 2016; 2017). This method considered the complete infiltration process, including high infiltration rates during the initial infiltration stage and decreases of infiltration rates approaching to steady-state conditions.

Vegetation is also one of the important factors influencing water infiltration. Previous studies have determined the relationships between vegetation and IR, highlighting that vegetation can alter water infiltration capacity of soils mostly by plant roots. It was found that the presence of vegetation can increase soil infiltrability. In arid reclaimed mine soils, Wu et al. $(2016 ; 2017)$, observed that high density root systems and root channels improved soil infiltrability by increasing the soil matrix water infiltration capacity. Meanwhile, the relationship between vegetation and infiltration is also affected by soil moisture (SM). Thompson et al. (2010) reported that the power law function between the infiltration capacity and the aboveground biomass increased in water-limited ecosystems, whereas vegetation biomass was not significantly related to infiltration capacity in humid regions. The results from several studies 
have revealed that plant roots could clog soil pores (Archer et al., 2002; Ng et al., 2013; Leung et al., 2015). In this context, there is a need to evaluate quantitatively the effects of plant roots on infiltration processes.

Cultivated grasslands have been paid much attention to control soil erosion and to restore hydrological processes in arid and semi-arid regions (Wu et al., 2016; 2017). In these landscapes, rainfall is the vital source of moisture and it is the only source of soil water for recharging aquifers. Therefore, one of the most important water resources for plant growth in water-limited areas is the stored soil water, which is supplemented by infiltrating rainfall (Dahan et al., 2007). Unquestionably, water infiltration into the soil is a key process that replenishes the root-zone SM in arid areas (Thompsom et al., 2010). However, previous studies so far were unable to explain the combined effects of soil moisture and plant roots on soil infiltration during the whole process. In this paper, we achieved this goal by measuring IR by the point source device at different cultivated grasslands in an arid area. Our tasks were to: (i) determine the effects of SM and plant roots on IR; and (ii) quantify the changes of these effects during the infiltration process. This study aimed to provide the evidence to disentangle the relative importance of SM and plant roots during the infiltration process.

\section{Study area and experiment design}

\subsection{Study sites}

This study was performed on the field site of a post-mining landform of the Yongli coal mine, which is located in Inner Mongolia Autonomous Region (China), in the northern Loess

Plateau. The regional climate is semiarid, with a mean annual temperature ca. $7.2^{\circ} \mathrm{C}$. The mean 
annual precipitation was $404 \mathrm{~mm}$ between 2010 and 2014, with $80 \%$ of the total annual rainfall registered in three months, from July to September. The annual actual evaporation was about $2082 \mathrm{~mm}$ and the annual cloud-free solar radiation was approximately $3119 \mathrm{~h}$. The climate is characterized by cold and dry air masses during the winter and spring, whereas the summer is rainy and hot.

The soil surface from this coalmine was mixed evenly by a large mixing machine before establishing the vegetation. The soil belongs to the Calcaric Cambisol series (FAO classification), texture is dominated by sandy soil, and the soil thickness is about $50 \mathrm{~cm}$. The mean soil fraction contents of sand, silt, and clay are 53\%, 42\%, and 5\%, respectively (determined by laser diffraction using a Mastersizer 2000, Malvern Instruments) (Wu et al., 2016).

\subsection{Experiment design}

Three cultivated grassland types, such as grasses, legumes, and mixed grasslands, were established for this study on a flat reclaimed land in June 2012. The two leguminous monoculture grasslands were Medicago sativa and Astragalus adsurgens, and the two gramineous monoculture grasslands were Agropyro mongolicum and Bromus inermis. The mixed sown grassland included seeds of Medicago sativa and Bromus inermis. Medicago sativa and Bromus inermis are the main species in cultivated grasslands in China. Astragalus adsurgens and Agropyro mongolicum are the dominant species in the region of this study, and are easy to survive in arid environments. The experiment was divided into two block groups, and six replicate plots $(3 \times 5 \mathrm{~m})$ were devoted to each grassland type. The details of the 
establishing plot for each grassland type have been introduced in $\mathrm{Wu}$ et al. (2017). The maintenance of the plots was done without nutrient supplementation and preventing animal disturbance. All plants had no artificial harvesting in order to keep the natural succession.

\section{Methods}

\subsection{Soil sampling and laboratory analysis}

The experimental measurements were mainly conducted in September. Three parallel quadrats, $1 \times 1 \mathrm{~m}$, were randomly selected in each plot for further study. The above-ground biomass was harvested on the ground level. According to the results of Wu et al. (2016) in a similar study area, plant roots are mainly distributed in the $0-30 \mathrm{~cm}$ soil layer. Root samples were collected using a $9 \mathrm{~cm}$ diameter root auger. Three samples were taken in turn form the center of the plants to the mid-way between the planting rows. The root samples were collected at three intervals of soil depth: 0-10 cm, 10-20 cm, and 20-30 cm. The different samples from the same layer were mixed to create a composite sample, which was repeated three times in each quadrat. Three repetitions were measured in each plot, with a total of 18 repetitions. Root samples were isolated by a $2 \mathrm{~mm}$ sieve, and then were oven-dried at $75^{\circ} \mathrm{C}$ to the constant mass.

Soil bulk samplers $\left(100 \mathrm{~cm}^{3}\right)$ were used to determine soil bulk density $\left(\mathrm{BD}, \mathrm{g} \mathrm{cm}^{-3}\right)$ at the same soil depth intervals of $0-10 \mathrm{~cm}, 10-20 \mathrm{~cm}$, and $20-30 \mathrm{~cm}$, and five replicates were conducted for each soil layer. The gravimetric soil water content (SWC, \%) was calculated by using the ratio of the loss of mass after oven drying at $105{ }^{\circ} \mathrm{C}$. The soil total porosity (TP, \%) was calculated by the formula $(1-\mathrm{BD} / \mathrm{PD}) \times 100$, where PD is the particle density $\left(\mathrm{g} \mathrm{cm}^{-3}\right)$, which was assumed to be $2.65 \mathrm{~g} \mathrm{~cm}^{-3}$. 


\subsection{Soil infiltration rate measurement}

The soil infiltration capacity automatic measurement system was used to determine the soil infiltration rate in each plot. This system was made up of a camera, a computer, a constant-flow pump, and a tripod. The peristaltic pump guaranteed a steady inflow of water on the soil surface. The camera automatically captured images of the wet area every 3 minutes. A numerical algorithm was used to calculate the soil infiltration rate (more details in Lei et al., 2006). The incorporation of the numerical algorithm allowed calculating the infiltration rates at different times (Lei et al., 2010; 2013). The following formula was used to determine the soil infiltration rate:

$$
i_{n}=\frac{q-\sum_{j=1}^{n-1} i_{j} \Delta A_{n-j+1}}{\Delta A_{n}}(n=1,2,3 \ldots)
$$

where $i_{n}$ is the soil infiltration rate at time $t_{n}\left(\mathrm{~mm} \mathrm{~h}^{-1}\right) ; q$ is the water flow rate (fixed at $3.0 \mathrm{~L} \mathrm{~h}^{-1}$ in this experiment); and $\Delta A_{n}$ is the increase of the wet area for a given time period $\left(t_{n}-t_{n-1}\right)$ $\left(\mathrm{mm}^{2}\right)$.

According to the methods of Wu et al. $(2016 ; 2017)$, the process of soil infiltration can be divided into five stages: (1) the initial 3 min are the initial infiltration stage, and the infiltration rate of this period is viewed as the initial infiltration rate (IIR); (2) the transient period, 3-15 min, and the infiltration rate is the average infiltration rate of stage I (AIRS I); (3) the gradually changing period, $15-45 \mathrm{~min}$, and the infiltration rate of this period is viewed as the average infiltration rate of stage II (AIRS II); (4) the stable period, 45-75 min, and the infiltration rate of this period is viewed as the average infiltration rate of stage III (AIRS III); and (5) the infiltration rate in the final $3 \mathrm{~min}$ is viewed as the average steady-state infiltration rate (SIR). 
The average infiltration rate during the $0-75 \mathrm{~min}$ period is defined as the overall average infiltration rate (AIR). At each measurement, the center of the grass was used as a point source of water supply. The infiltration rate in each plot was repeated three times.

\subsection{Statistical analysis}

Soil properties in the different grasslands were analyzed by Linear mixed-effect modelling. The species composition of each plot was used as fixed effect in the analyses, and block and plot (nested within block) were used as random effects. The function 'lme' in the package 'nlme' (Pinheiro et al., 2016) was used for linear mixed-effects modeling in R statistical software (version 3.3.1; R Development Core Team 2016). The Stepwise regression analysis was conducted to explore the relationships between the soil water content, the below-ground biomass (BGB), and the soil infiltration rate at different stages. The linear regression analysis was used to determine the relationships between the soil water content, and BGB in the different soil layers, and the soil infiltration rate over time. The coefficient of determination $\left(\mathrm{R}^{2}\right)$ of each linear regression analysis was used to analyse the influence degrees of the water content and root biomass on the infiltration rate during the duration of the different infiltration stages. The regression analysis was conducted to identify the relationships between $\mathrm{R}^{2}$ and infiltration time. In the regression analysis, the IIR, AIRS I, AIR, AIRS II, AIR III, and SIR represented the infiltration rate at $3,7.5,30,37.5,60$ and $75 \mathrm{~min}$, respectively. These time points are the average of the five stages and the average infiltration. The water content and root biomass at the different soil depth layers were considered as the repetitions ( 3 in root biomass, and 5 in soil water content). Multiple comparisons were test through Tukey's post hoc test and the significant 
differences at the 0.05 level. All data were expressed as the mean \pm the square error $(M \pm$ s.e. $)$.

\section{Results}

\subsection{Soil infiltration rates at the different stages}

The mixed grassland had the highest soil organic matter (SOM) and the lowest $\mathrm{BD}$ at the $0-30$ $\mathrm{cm}$ soil depth layer among all the grasslands (Table 2). The TP at the $0-10 \mathrm{~cm}$ soil depth was higher in the mixed grassland than in the gramineous and leguminous grasslands. The SOM and TP decreased with increasing the soil depth, although BD increased with increasing soil depth in all grasslands.

IIR was significantly higher in the leguminous grassland than in the gramineous and mixed grasslands $(p<0.05$; Table 3$)$. The mixed grassland showed the greatest soil infiltration rate in the infiltration stage II and the stage III, but the leguminous grassland showed the greatest soil infiltration rate in the infiltration stage I.

\subsection{Effects of soil moisture and root biomass on the soil infiltration rates}

The below-ground biomass (BGB) was significantly greater at the $0-10 \mathrm{~cm}$ soil layer than at the 10-20 and 20-30 cm soil layers ( $p<0.01$; Fig. 1 ). The plant roots were mainly distributed at the topsoil layer, which accounted for $87.46 \%, 80.69 \%$, and $87.45 \%$ of the total BGB in the gramineous, leguminous, and mixed grasslands, respectively. Root biomass at the $10-20 \mathrm{~cm}$ soil layer was higher in the leguminous grassland than in the gramineous and mixed grasslands $(p<$ $0.05)$.

The regression analysis results showed that SWC had a significant effect in the initial 
infiltration stage, but both SWC and BGB were the main factors influencing infiltration rate in the steady-state infiltration stage (Table 4). SWC was significantly and negatively correlated to IIR in the leguminous and the mixed grasslands. IIR and AIRS II were clearly affected by SWC at the topsoil layer $(0-10 \mathrm{~cm}$ depth) in the gramineous and the leguminous grasslands. This influence of SWC was limited to the mixed grassland at the $10-20 \mathrm{~cm}$ soil layer $(p<0.001)$. AIRS III was affected by SWC at the topsoil layer, and by BGB at the depth of $10-20 \mathrm{~cm}(p<$ 0.001) in the gramineous grassland. AIRS III depended on BGB and SWC in the topsoil layer ( $p$ $<0.001)$ in the leguminous grassland. In the mixed grassland, AIRS III was affected by BGB in the topsoil layer, and by SWC in the $10-20 \mathrm{~cm}$ and $30-40 \mathrm{~cm}$ soil layers $(p<0.001)$.

\subsection{Relationships between $S W C, B G B$ and the infiltration rates}

SWC before infiltration was not homogeneous, following this pattern: gramineous grassland > mixed grassland > leguminous grassland at the depth of 0-50 $\mathrm{cm}$ soil layer (Fig.2). The SWC at the depth of $20-40 \mathrm{~cm}$ was significantly lower in the leguminous grassland than in gramineous and mixed grasslands. The water infiltration depths were 32,36 and more than 50 $\mathrm{cm}$ in the gramineous, leguminous, and mixed grasslands, respectively (Fig.3). The relationship between the coefficient of determination and the infiltration time showed a negative correlation whether in SWC and BGB (Fig.4). The slope of the linear regression was greater in the SWC than in the BGB.

\section{Discussion}

\subsection{Effects of soil moisture on infiltration}


Soil infiltration rate (IR) is a key variable in soil particle and sediment delivery processes, and it impacts on fertilization efficiency, environmental quality, and water conservation (Assouline, 2013). The process of infiltration is a complex physical process, which is difficult to characterize accurately for the isotropic and heterogeneous conditions commonly found in the field experiments. Many biotic and abiotic factors can affect IR directly or indirectly. At field scale, water infiltration is mostly determined by the spatial variability of rainfall intensity and soil hydraulic properties. One important source of error that can dominate or suppress other factors is the initial soil moisture (Fischer et al., 2014).

The initial soil water content was negatively correlated with IR in our study. This result was consistent with the results of previous studies (Liu et al., 2011; Assoiline, 2013; Fouli et al., 2013), which have proposed that higher initial soil moisture may lead to a reduction of IR. It is known that the soil water content mainly affects infiltration capacity through the soil matric potential and determines the degree of soil saturation. An increase in soil moisture diminishes the hydraulic gradient, thus decreasing the driving force responsible for water infiltration into the soil (Liu et al., 2011). The soil remains in the unsaturated state at the beginning of the infiltration, and the infiltration rate is controlled by the soil water matric potential and the large pore flow of the soil (Philip, 1958). The smaller the initial water content, the lower the soil water potential, the greater suction to the water molecules, and the faster infiltration of soil moisture. On the other hand, soil dryness leads to many cracks among aggregates, which results to higher infiltration rates. With water infiltration, the soil water content and potential increased, and the infiltration rate decreased due to the crack decrease after the aggregate expansion.

The water infiltration into the soil diminishes when the soil moisture increases. The higher 
soil moisture content may lead to greater swelling of clay particles in the soil, which causes reductions in soil pore and hydraulic gradient. According to the results from Philip (1958), the matric and gravitational forces during infiltration were the main reason causing the changes of the wetting front. The wetted zone moved toward the area of lower moisture tension due to the higher rate of water flow towards this area and specially to the higher soil water permeability. Therefore, with the decrease of permeability, the soil infiltration rate is reduced under the higher soil moisture content. Natural soil profiles are rarely homogeneous with depth and generally present successive different soil layers with different hydraulic properties. At the initial stage of the infiltration, low initial soil water content favoured the water flow through the soil due to the larger gradients in matric potential, filling up the soil storage. The topsoil water content (SWC at the $0-10 \mathrm{~cm}$ depth soil layer) was the main factor influencing infiltration in our study. With the duration of the infiltration, the effect of the initial water content decreased, because the soil pores probably were filled and infiltration approached to a steady-state condition that is called steady infiltration rate. The coefficient of determination between soil moisture and soil infiltration rate was negatively related to the infiltration time, which was a reliable interpretation for the previous results.

\subsection{Effects of soil moisture and plant roots on infiltration}

Soil moisture strongly influences infiltration capacity but the coefficients of determination between soil moisture and infiltration rate decreased gradually at a rate of 0.0005 per minute. Therefore, the effect of plant roots on infiltration was important in the initial infiltration stage and gradually diminished until the steady-state stage of the infiltration. The positive feedback 
that the plant roots made increasing infiltration capacity was showed in our study. Macropores and root channel formed by the root system of the plants were vital channels for water infiltration. Moreover, plant roots enmesh and realign soil particles and release exudates resulting in physical, chemical, and biological alterations in the soils, which in turn impact the soil permeability (Bronick and Lal, 2005). The root biomass was positively related to the soil infiltration rates, and this relationship was a contrary trend compared with that obtained with the soil moisture. But soil moisture and roots showed the same tendency of decreasing influence on infiltration over time. Roots became one of the main factors that influenced infiltration during the infiltration process, which results from the lower slope (0.0004 in our study) between infiltration time and coefficients of determination.

The leguminous and the mixed grasslands increased infiltration capacity compared with the gramineous grasslands. These differences can be explained because the leguminous grasslands showed the lowest initial soil water content in this study. This result is consistent with the research of Huang et al. (2017), who reported that legumes have higher water consumption capacity compared with grasses. Previous studies have showed that water infiltration was increased by the leguminous or legumes-grasses mixed grasslands compared to the gramineous grassland due to the differences of root types. Wu et al. (2016) reported that legumes-grassed mixed cultivated grasslands improved soil infiltration capacity as a result of their greater root biomasses. Meanwhile, root channels encourage higher soil infiltration rates in leguminous and mixed grasslands in arid mine soils (Wu et al., 2017). The decaying tap-roots of legumes form stable macropores and increase water infiltration (Fischer et al., 2014). Because the root systems promote water infiltration, the spatial distribution of roots may cause differences of infiltration 
depth in the soil profile. This conclusion was confirmed by our results, which showed that the infiltration depth was higher in the leguminous and mixed grasslands than in the gramineous grassland (Fig.3). The different root systems affected the hydraulic properties via different mechanisms, and thus further research is necessary to interpret the links between the root characteristics and the infiltration response. This task will be of especial interest for arid areas.

\section{Conclusions}

Soil moisture and plant roots significantly affected the infiltration process in three different grasslands under semiarid cold conditions. Soil infiltration rate was negatively related to the soil water content, but it was positively correlated with the below-ground biomass. Soil moisture was the main factor influencing the soil water infiltration capacity during the initial stage, and both soil moisture and plant roots determined the infiltration rates during the steady-state stage. The influences of soil moisture and plant roots diminished with the duration of infiltration time. The rate of decreasing influence showed that soil moisture influenced more than plant roots, so that the plant roots became another main determination factor in the steady-state stage. These results contributed to interpret the higher infiltration capacity observed in the soil of the leguminous grasslands than in the soil of the gramineous and mixed grasslands. Further work is needed to discriminate the influence mechanism of the different root types on the soil hydraulic properties to better determine the relationships between vegetation and infiltration in the arid and semiarid areas.

\section{Acknowledgements}


This research was funded by the Projects of the Natural Science Foundation of China (NSFC 41722107), the Light of West China Program of the Chinese Academy of Sciences (XAB2015A04; XAB2018B09), the Youth Innovation Promotion Association of the Chinese Academy of Sciences (\#2011288), and the Youth Talent Plan Foundation of the Northwest A\&F University (\#2452018025).

\section{References}

Angulo-Jaramillo, R., Vandervaere, J.P., Roulier, S., Thony, J.L., Gaudet, J.P., Vauclin, M., 2000. Field measurement of soil surface hydraulic properties by disc and ring infiltrometers a review and recent developments. Soil Till. Res. $55,1-29$.

Archer, N.A.L., Quinton, J.N., Hess, T.M., 2002. Below-ground relationships of soil texture, roots and hydraulic conductivity in two-phase mosaic vegetation in south-east Spain. J. Arid Environ. 52, 535-553.

Assouline, S., 2013. Infiltration into soils: Conceptual approaches and solutions. Water Resour. Res. 49, 1755-1772.

Bronick, C.J., Lal, R., 2005. Soil structure and management: a review. Geoderma 124, 3-22.

Capowiez, Y., Cadoux, S., Bouchant, P., Ruy, S., Roger-Estrade, J., Richard, G., Boizard, H., 2009. The effect of tillage type and cropping system on earthworm communities, macroporosity and water infiltration. Soil Till. Res. 105, 209-216.

Cerdà, A., 1997. Seasonal changes of the infiltration rates in a mediterranean scrubland on limestone. J. Hydrol. 198, $209-225$.

Cheng, Q.B., Chen, X., Chen, X.H., Zhang, Z.C., Ling, M.H., 2011. Water infiltration underneath single-ring permeameters and hydraulic conductivity determination. J. Hydrol. 398, 135-143.

Dahan, O., Shani, Y., Enzel, Y., Yechieli, Y., Yakirevich, A., 2007. Direct measurements of floodwater infiltration into shallow alluvial aquifers. J. Hydrol. 344, 157-170. 
Dekker, L.W., Ritsema, C.J., 1994. How water move in a water repellent sandy soil: 1 Potential and actual water repellency. Water Res. Res. 30, 2507-2517.

Ebel, B.A., Moody, J.A., 2013. Rethinking infiltration in wildfire-affected soils. Hydrol. Process. 27, 1510-1514.

Fischer, C., Roscher, C., Jensen, B., Eisenhauer, N., Baase, J., Attinger, S., Scheu, S., Weisser, W.W., Schumacher, J., Hildebrandt, A., 2014. How do earthworms, soil texture and plant composition affect infiltration along an experimental plant diversity gradient in grassland? PLoS ONE 9, e98987.

Fouli Y, Cade-Menun BJ, Cutforth, H.W., 2013. Freeze-thaw cycles and soil water content effects on infiltration rate of three Saskatchewan soils. Can. J. Soil. Sci. 93,485-496.

Huang, Z., Tian, F.P., Wu, G.L., Liu, Y., Dang, Z.Q., 2017. Legume grasslands promote precipitation infiltration better than gramineous grasslands in arid regions. Land Degrad. Develop. 28, 309-316.

Lei, T.W., Chuo, R.Y., Zhao, J., Shi, X.N., Liu, L. 2010. An improved method for shallow water flow velocity measurement with practical electrolyte input. J. Hydrol. 390, 45-56.

Lei, T.W., Mao, L.L., Li, X., Liu, H., Huang, X.F., Zhang, Y.N., 2007. Method for measuring soil infiltrability with linear run-on of water. Trans. Chin. Soc. Agric. Eng. 23, 1-5 (in Chinese).

Lei, T.W., Pan, Y.H., Liu, H., Zhan, W.H., Yuan, J.P., 2006. A run off-on-out method and models for the transient infiltrability process of slope soil surface under rainfall and erosion impacts. J. Hydrol. 319, 216-226.

Lei, T.W., Yan, Y., Shi, X.N., Chuo, R.Y., Zhao, J., 2013. Measuring velocity of water flow within gravel layer with electrolyte tracer method under pulse boundary model. J. Hydrol. 500, 37-44.

Leung, A.K., Garg, A., Coo, J.L., Ng, C.W.W., Hau, B.C.H., 2015. Effects of the roots of Cynodon dactylon and Schefflera heptaphylla on water infiltration rate and soil hydraulic conductivity. Hydrol. Process. 29, 3342-3354.

Liu, H., Lei, T.W., Zhao, J., Yuan, C.P., Fan, Y.T., Qu, L.Q., 2011. Effects of rainfall intensity and antecedent soil water content on soil infiltrability under rainfall conditions using the run off-on-out method. J. Hydrol. 396, 24-32. 
Lubana, P.P.S., Narda, N.K., 2001. Modelling soil water dynamic under trickle emitters - a review. J. Agric. Eng. Res.

$$
\text { 78, 217-232. }
$$

Mao, L.L., Lei, T.W., Li, X., Liu, H., Huang, X.F., Zhang, Y.N., 2008. A linear source method for soil infiltrability measurement and model representations. J. Hydrol. 353, 49-58.

Mao, L.L., Lei, T.W., Bralts, V.F., 2011. An analytical approximation method for the linear source soil infiltrability measurement and its application. J. Hydrol. 411, 169-177.

Mao, L.L., Li, Y.Z., Hao, W.P., Mei, X.R., Bralts, V.F., Li, H.R., Guo, R., Lei, T.W., 2016. An approximate point source method for soil infiltration process measurement. Geoderma 264, 10-16.

Ng, C.W.W., Woon, K.X., Leung, A.K., Chu, L.M., 2013. Experimental investigation of induced suction distributions in a grass-covered soil. Ecol. Eng. 52, 219-223.

Philip, J.R., 1958. The theory of infiltration: 5. The influence of the initial moisture content. Soil Sci. 84, 329-339.

Pinheiro, J., Bates, D., DebRoy, S., R Core Team (2016) nlme: Linear and Nonlinear Mixed Effects Models. R package version 3.1-128, <https://CRAN.R-project.org/package=nlme>

Revol, P., Cauclin, M., Vachaud, G., Clothier, B.E., 1997. Infiltration from a surface point source and drip irrigation: 1 The midpoint soil water pressure. Water Resour. Res. 33, 1861-1867.

Shani, U., Hanks, R.J., Bresler, E., Oliveria, C.A.S., 1987. Field method of estimating hydraulic conductivity and matric potential-water content relations. Soil Sci. Soc. Am. J. 51, 298-302.

Su, N.H., 2007. Radial water infiltration-advance-evaporation processes during irrigation using point source emitters in rigid and swelling soils. J. Hydrol. 344, 190-197.

Thompson, S.E., Harman, C.J., Heine, P., Katul, G.G., 2010. Vegetation-infiltration relationship across climatic and soil type gradients. J. Geophys. Res. 115, G02023.

Wu, G.L., Yang, Z., Cui, Z., Liu, Y., Fang, N.F., Shi, Z.H., 2016. Mixed artificial grasslands with more roots improved 
mine soil infiltration capacity. J. Hydrol. 535, 54-60.

Wu, G.L., Liu, Y., Yang, Z., Cui, Z., Deng, L., Chang, X.F., Shi, Z.H., 2017. Root channels to indicate the increase in soil matrix water infiltration capacity of arid reclaimed mine soils. J. Hydrol. 546, 133-139.

Xu, M.X., Liu, G.B., Bu, C.F., Jia, H.Y., 2002. Experimental study on soil infiltration characteristics using disc permeameter. Trans. Chin. Soc. Agric. Eng. 18,54-58 (in Chinese).

Youngs, E.G., 1991, Infiltration measurements - a review. Hydrol. Process. 5,309-320.

Zhang, J., Lei, T.W., Chen, T.Q., 2016. Impact of preferential and lateral flows of water on single-ring measured infiltration process and its analysis. Soil Sci. Soc. Am. J. 80,859-869. 
Table 1. Summary of strengths and weaknesses of several infiltration measurement methods in recent relevant literature which were studied on the Loess Plateau.

\begin{tabular}{|c|c|c|c|}
\hline Methods & Strengths & Weakness & Study \\
\hline Double-ring method & $\begin{array}{l}\text { Vertical infiltration } \\
\text { Outer ring prevents lateral infiltration } \\
\text { Deep infiltration depth }(>50 \mathrm{~cm}) \\
\text { Large infiltration area }\end{array}$ & $\begin{array}{l}\text { The inability to measure very high initial infiltration } \\
\text { rates due to an insufficient water supply } \\
\text { Disturbing the surface conditions when installed rings } \\
\text { A crust is formed at the soil surface duo to fast wetting } \\
\text { when water is poured into the two rings }\end{array}$ & $\begin{array}{l}\text { Xu et al., } 2002 \\
\text { Mao et al., } 2016\end{array}$ \\
\hline Disc permeameter & $\begin{array}{l}\text { Undisturbed soil surface conditions } \\
\text { Determined initial infiltration process quantitatively } \\
\text { Accurate reading }\end{array}$ & $\begin{array}{l}\text { Small infiltration area } \\
\text { Shallow infiltration depth }(20-30 \mathrm{~cm}) \\
\text { Slightly lateral infiltration }\end{array}$ & Xu et al., 2002 \\
\hline Rainfall simulator & $\begin{array}{l}\text { Fully simulated nature rainfall conditions; } \\
\text { Rainfall intensity can be controlled }\end{array}$ & $\begin{array}{l}\text { The inability to measure very high initial infiltration } \\
\text { rates due to an insufficient water supply } \\
\text { Maximum infiltration rate is rainfall intensity } \\
\text { Large amount of water consumption } \\
\text { Difficulty in installation }\end{array}$ & Lei et al., 2006 \\
\hline Single-ring method & $\begin{array}{l}\text { Simple structure, easy operation, portability } \\
\text { Small amount of recharging water compared double-ring }\end{array}$ & $\begin{array}{l}\text { Similar to the double-ring method } \\
\text { Lateral infiltration }\end{array}$ & Zhang et al., 2016 \\
\hline Linear source method & $\begin{array}{l}\text { Measurable the whole infiltration process } \\
\text { Measurable slope infiltration }\end{array}$ & Unable to simulate natural rainfall & $\begin{array}{l}\text { Lei et al., 2007; } \\
\text { Mao et al., } 2011\end{array}$ \\
\hline Point source method & $\begin{array}{l}\text { Similar to the linear source method } \\
\text { Small amount of water consumption } \\
\text { Simple, fast and efficient relative to the linear source } \\
\text { method, Suitable for field measurement }\end{array}$ & Unable to simulate natural rainfall & Mao et al., 2016 \\
\hline
\end{tabular}


Table 2. Soil properties ( $M \pm$ s.e.) in three soil layers up to $30 \mathrm{~cm}$ soil depth in different cultivated grasslands.

\begin{tabular}{lllll}
\hline Soil properties & Layer & Grass & Legume & Mixture \\
\hline SOM $\left(\mathrm{g} \mathrm{kg}^{-1}\right)$ & $0-10 \mathrm{~cm}$ & $8.02 \pm 0.71$ & $7.83 \pm 0.35$ & $9.43 \pm 0.52$ \\
& $10-20 \mathrm{~cm}$ & $5.00 \pm 0.61$ & $5.91 \pm 0.36$ & $8.79 \pm 0.63$ \\
& $20-30 \mathrm{~cm}$ & $4.80 \pm 0.53$ & $5.89 \pm 0.59$ & $6.30 \pm 0.13$ \\
$\mathrm{BD}\left(\mathrm{g} \mathrm{cm}^{-3}\right)$ & $0-10 \mathrm{~cm}$ & $1.42 \pm 0.02$ & $1.42 \pm 0.01$ & $1.37 \pm 0.03$ \\
& $10-20 \mathrm{~cm}$ & $1.57 \pm 0.02$ & $1.60 \pm 0.02$ & $1.57 \pm 0.01$ \\
& $20-30 \mathrm{~cm}$ & $1.64 \pm 0.02$ & $1.62 \pm 0.01$ & $1.64 \pm 0.02$ \\
$\operatorname{TP}(\%)$ & $0-10 \mathrm{~cm}$ & $46.29 \pm 0.75$ & $46.39 \pm 0.48$ & $48.40 \pm 1.00$ \\
& $10-20 \mathrm{~cm}$ & $40.82 \pm 0.59$ & $39.81 \pm 0.58$ & $40.81 \pm 0.28$ \\
& $20-30 \mathrm{~cm}$ & $38.17 \pm 0.61$ & $39.06 \pm 0.50$ & $38.27 \pm 0.84$ \\
\hline
\end{tabular}

Note: Mixture represents Grass + Legume; SOM represents soil organic matter; BD

represents soil bulk density; TP represents soil total porosity. 
Table 3. Soil infiltration rates $\left(\mathrm{M} \pm\right.$ s.e.; $\left.\mathrm{mm} \mathrm{h}^{-1}\right)$ in the different cultivated grasslands.

\begin{tabular}{lcccccc}
\hline Grassland types & IIR & SIR & AIR & AIRS I & AIRS II & SIRS III \\
\hline Grass & $83.21 \pm 6.43$ & $12.04 \pm 1.02$ & $22.96 \pm 1.42$ & $47.03 \pm 3.30$ & $18.21 \pm 1.49$ & $12.90 \pm 1.18$ \\
Legume & $112.17 \pm 8.41$ & $12.56 \pm 1.04$ & $24.24 \pm 1.65$ & $54.64 \pm 4.00$ & $19.10 \pm 1.68$ & $12.96 \pm 1.21$ \\
Mixture & $81.27 \pm 7.00$ & $12.47 \pm 2.32$ & $24.19 \pm 3.01$ & $54.48 \pm 7.69$ & $19.48 \pm 2.98$ & $13.72 \pm 2.49$
\end{tabular}

Note: Mixture represents Grass + Legume; IIR represents initial infiltration rate; SIR

represents steady infiltration rate; AIR represents average infiltration rate; AIRS I, II and III represent the average infiltration rate in stage I, II and III, respectively. 
Table 4. Results of the stepwise regression analysis. The below-ground biomass $\left(\mathrm{g} \mathrm{m}^{-2}\right)$ and soil water content $(\%)$ were considered as independent variable in stepwise regression $(n=18)$. If there is no independent variable in the stepwise regression, backward is used in regression analysis.

\begin{tabular}{|c|c|c|c|c|c|c|}
\hline Grassland types & $\begin{array}{l}\text { Dependent } \\
\text { variable }\end{array}$ & Independent variable & $\mathrm{R}$ & $\mathrm{F}$ & $\mathrm{p}$ & Coefficient \\
\hline \multirow[t]{7}{*}{ Grass } & IIR & SWC 0-10 & 0.47 & 6.96 & 0.14 & -4.484 \\
\hline & SIR & SWC 0-10 & 0.83 & 53.00 & $<0.001$ & -1.236 \\
\hline & AIR & SWC 0-10 & 0.78 & 38.11 & $<0.001$ & -1.622 \\
\hline & AIRS I & SWC 0-10 & 0.53 & 10.11 & 0.004 & -2.630 \\
\hline & AIRS II & SWC 0-10 & 0.82 & 52.22 & $<0.001$ & -1.851 \\
\hline & AIRS III & SWC 0-10 & 0.82 & 25.11 & $<0.001$ & -1.294 \\
\hline & & BGB 10-20 & & & & 0.003 \\
\hline \multirow[t]{8}{*}{ Legume } & IIR & SWC 0-10 & 0.43 & 4.72 & 0.041 & -4.366 \\
\hline & SIR & BGB 0-10 & 0.65 & 8.02 & 0.002 & 0.004 \\
\hline & & SWC 0-10 & & & & -0.801 \\
\hline & AIR & SWC 0-10 & 0.70 & 21.85 & $<0.001$ & -1.356 \\
\hline & AIRS I & SWC 0-10 & 0.73 & 26.64 & $<0.001$ & -3.452 \\
\hline & AIRS II & SWC 0-10 & 0.67 & 19.17 & $<0.001$ & -1.330 \\
\hline & AIRS III & BGB 0-10 & 0.70 & 10.55 & $<0.001$ & 0.004 \\
\hline & & SWC 0-10 & & & & -1.025 \\
\hline \multirow[t]{11}{*}{ Mixture } & IIR & SWC 10-20 & 0.54 & 5.47 & 0.036 & -3.589 \\
\hline & SIR & SWC 10-20 & 0.58 & 3.50 & 0.059 & -1.89 \\
\hline & & SWC 30-40 & & & & 1.433 \\
\hline & AIR & BGB 0-10 & 0.74 & 8.40 & 0.004 & 0.009 \\
\hline & & SWC 10-20 & & & & -1.700 \\
\hline & AIRS I & SWC 30-40 & 0.77 & 10.11 & 0.002 & -4.231 \\
\hline & & BGB 0-10 & & & & 0.029 \\
\hline & AIRS II & SWC 10-20 & 0.48 & 4.58 & 0.049 & -1.442 \\
\hline & AIRS III & BGB 0-10 & 0.70 & 3.91 & 0.037 & 0.001 \\
\hline & & SWC 10-20 & & & & -1.185 \\
\hline & & SWC 30-40 & & & & 1.089 \\
\hline
\end{tabular}

Note: Mixture represents Grass + Legume; IIR represents initial infiltration rate; SIR represents steady infiltration rate; AIR represents average infiltration rate; AIRS I, II and III represent the average infiltration rate in stage I, II and III, respectively. BGB 0-10 represents the below-ground biomass at the depth of 0-10 cm soil layer; SWC 0-10 represents the soil water content at the depth of $0-10 \mathrm{~cm}$ soil layer; the rest are similar. 


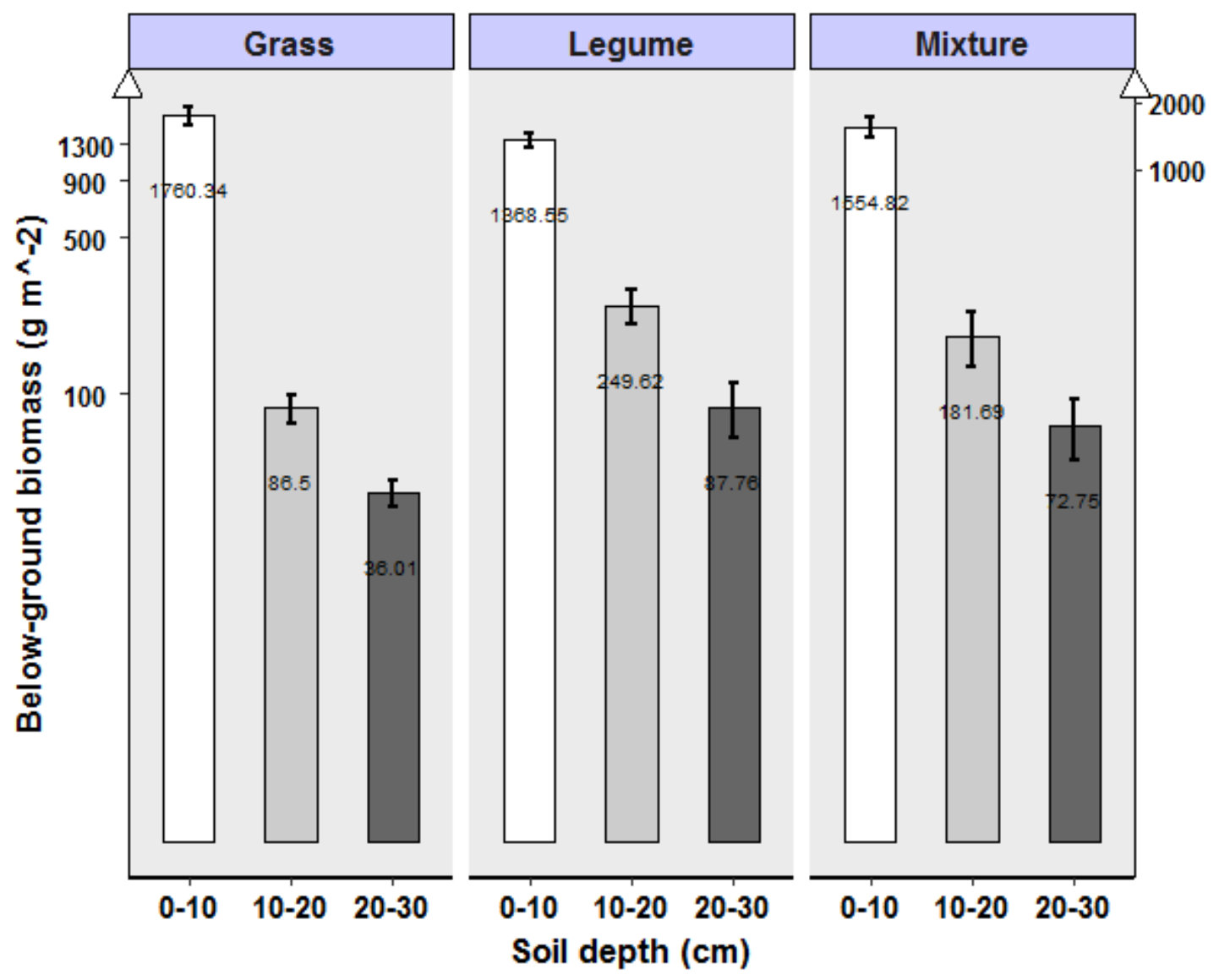

Fig. 1. Root biomass $(0-30 \mathrm{~cm}$ soil depth) in the different cultivated grasslands. Mixture represents Grass + Legume. 


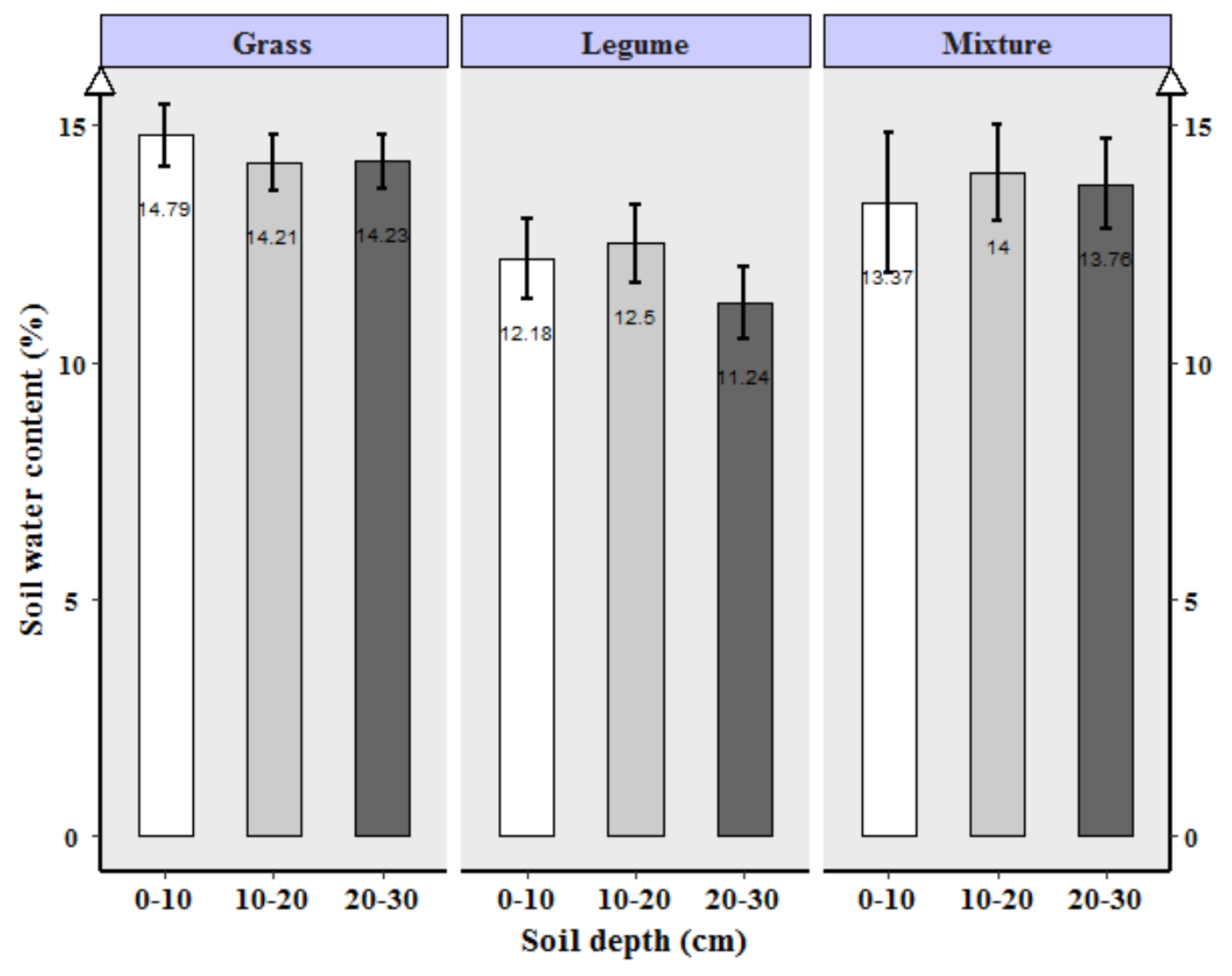

Fig. 2. Soil water content $(0-50 \mathrm{~cm}$ soil depth) before infiltration in the different cultivated grasslands. Mixture represents Grass + Legume. 


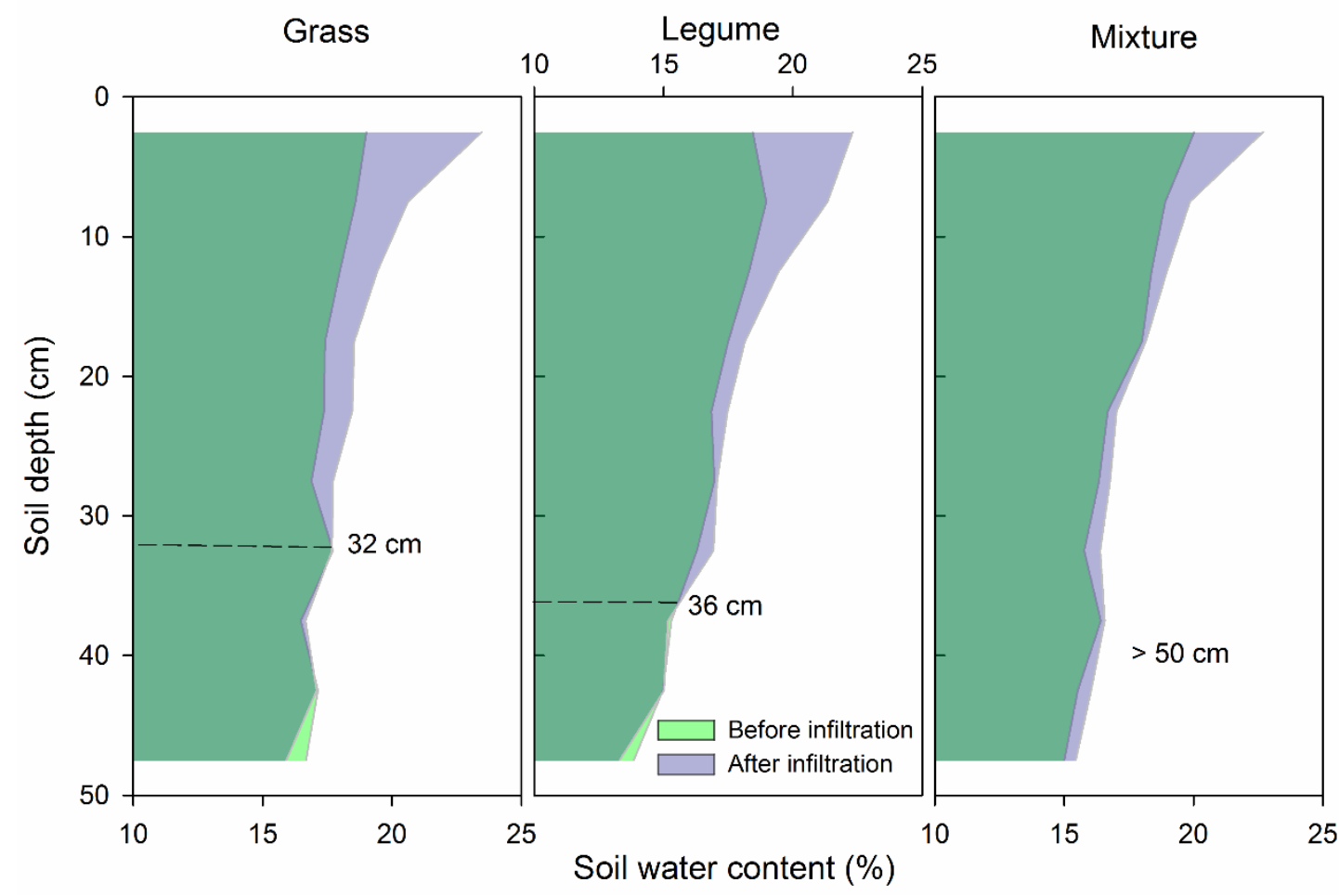

Fig. 3. Water infiltration depth in the different cultivated grasslands. The soil water content (SWC) before and after infiltration has an intersection point in the figure. In the upper layer of the intersection, SWC after infiltration was significantly higher than that before infiltration. In the lower layer of the intersection, SWC before and after infiltration is basically equal. Therefore, soil infiltration depth was determined by the intersection point of SWC before and after infiltration. Mixture represents Grass + Legume grassland. 


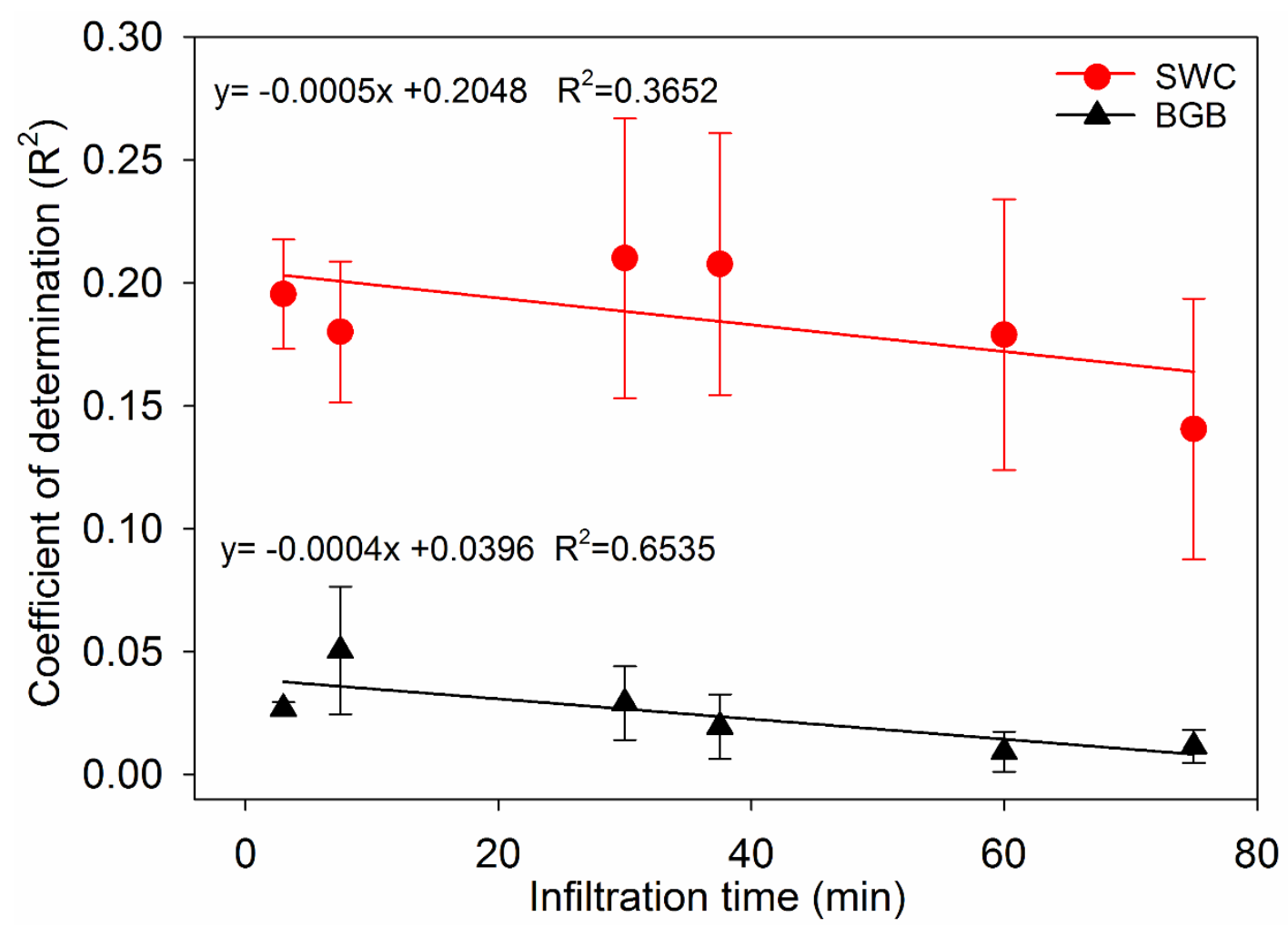

Fig. 4. Relationships between the coefficients of determination and the infiltration time (SWC, $\mathrm{n}=5$; $\mathrm{BGB}, \mathrm{n}=3$ ). SWC represents the soil water content, and BGB represents the below-ground biomass. 